\title{
A REGIÃO CULTURAL COMO CATEGORIA DE ANÁLISE DA MATERIALIZAÇÃO DA CULTURA NO ESPAÇO GAÚCHO
}

\section{The cultural region as category of the materialization of the culture in the gaúcho space}

\author{
Helena Brum NETO1 \\ Meri Lourdes BEZZI ${ }^{2}$
}

\begin{abstract}
RESUMO
A questão regional, na atualidade, apresenta distintas perspectivas de análise as quais podem ser evidenciadas mediante as transformações impostas pelo processo de globalização na organização do espaço. Nesta perspectiva, esse artigo propõe refletir acerca da região sob a ótica da cultura, considerando-a como um verdadeiro agente dinamizador dos recortes espaciais, uma vez que os mesmos se constituem em um dos pilares estruturais que impedem a homogeneização dos códigos culturais, responsabilizando-se pela diversidade de formas de organização do espaço. O conceito de região é enfocado através de processos simbólicos inerentes à cultura, a qual materializa, no espaço, as suas formas características, originando recortes regionais com conotação cultural, ou seja, as regiões culturais. Para exemplificar tais reflexões, aborda-se o contexto regional do Rio Grande do Sul, no qual, o regionalismo torna-se evidente mediante a construção do gaúcho como tipo regional representativo da unidade na diversidade.
\end{abstract}

Palavras-chave: Região cultural; Identidade Cultural; Questão Regional; Códigos Culturais; Globalização.

\begin{abstract}
The regional matter, at the present time, presents different analysis perspectives which can be evidenced by the transformations imposed by the globalization process in the space organization. In this perspective, this paper intends to consider the area under the optics of culture, considering it as a true promoter agent of the space cuttings, once they are constituted in one of the structural pillars that obstruct the homogenization of the cultural codes, taking the responsibility for the diversity in ways of organization of the space. The concept of region is focused through symbolic processes inherent to culture, which materializes, in the space, its characteristic forms, originating regional cuttings with cultural connotation, in other words, the cultural areas. To exemplify such reflections, the regional context of Rio Grande do Sul is approached, in which, the regionalism becomes evident by the construction of the "gaúcho" as a representative regional type of the unit in the diversity.
\end{abstract}

Keywords: Cultural Region; Cultural Identity; Regional Matter; Cultural Codes; Globalization. Agrários NERA/CCNE/UFSM. 
NETO, H. B.; BEZZI, M. L. A região cultural como categoria de análise...

\section{INTRODUÇÃO}

A região, como categoria de análise do espaço para a Geografia, ao mesmo tempo em que demonstra as similaridades espaciais, faz com que as diferenças se evidenciem, salientando os recortes regionais que apresentam distintas formas de organização espacial. Essa categoria de análise reflete a relação sociedadenatureza, uma vez que o uso do espaço e da técnica, no decorrer do tempo, apresenta-se de forma desigual, pois as atividades desenvolvidas pelo homem expressam um processo contínuo de transformação segundo os períodos históricos e os estágios técnicos assumidos por determinada sociedade.

Pode-se dizer então, que, o espaço regional é heterogêneo e, portanto, individualizado por recortes estabelecidos de acordo com critérios específicos, já que a ordem espaço-temporal ocorre em resposta à necessidade de cada tipo de produção e de relações sociais. Ao se considerar o homem como um ser cultural, pode-se dizer que, sua relação com a natureza é mediada por distintos códigos culturais (sistemas simbólicos de representação originados por um grupo social), que se abrem frente aos interesses do capital, ao novo, mas, muitas vezes, resiste às mudanças, às transformações, e à primeira lei social para manter a herança cultural.

Nesse sentido, este artigo busca enfatizar a abordagem regional centrando sua análise através da ótica cultural, ou seja, propõe refletir e analisar acerca da região cultural. Para tal, enfatizam-se as diferentes perspectivas de análise da questão regional sob a orientação cultural, além de enfocar as transformações impostas a relação sociedade-natureza pelo processo de globalização e suas consequências na organização do espaço. Desse modo, pôde-se inferir a representatividade da cultura como um dos pilares estruturais que impedem a homogeneização dos costumes, responsabilizando-se pela diversidade de formas e arranjos espaciais.

A questão regional enfocada pela simbologia inerente à cultura permite resgatar a subjetividade dos recortes regionais atreladas à materialidade do espaço, ou seja, aliam os aspectos materiais aos imateriais. A compreensão da(s) cultura(s) regional(is) torna-se complexa à medida em que se pressupõe unir os dados científicos aos sentidos humanos, pois a apreensão da paisagem, é fundamental para entender a organização do espaço por um determinado grupo cultural.

Nesta perspectiva, o conceito de região é enfocado através de processos simbólicos inerentes à cultura, a qual materializa no espaço as suas formas caracte- rísticas, originando recortes espaciais com conotação cultural, ou seja, as regiões culturais. Para exemplificar tais reflexões, procurou-se abordar o contexto regional do Rio Grande do Sul, como uma das Unidades da Federação brasileira onde o regionalismo torna-se evidente, mediante a construção do gaúcho como tipo regional representativo de uma "unidade na diversidade".

Com esse intuito, resgatou-se a análise cultural buscando desmistificar a "figura do gaúcho", muitas vezes utilizada de forma taxativa, generalizando a sociedade gaúcha a partir de um tipo regional único. Salienta-se que todo processo de regionalização pressupõe uma generalização. Entretanto, no presente artigo propõe-se demonstrar, através de exemplos práticos, as particularidades intrínsecas ao contexto regional, uma vez que, o Rio Grande do Sul tem sua composição étnica variada, que corresponde a períodos específicos de inserção de correntes migratórias distintas e, por sua vez, responsáveis pela sua construção cultural diversificada no decorrer da evolução histórica do território riograndense.

Tal situação acarreta uma análise minuciosa do contexto regional, para que se possa compreendê-lo na sua totalidade, ou seja, procuraram-se respostas referentes à questão da construção da identidade, ou mesmo, das identidades gaúchas no âmbito da cultura e do regionalismo. Esse, por sua vez, configura-se como um produto simbólico de representação e de identificação, oriundo da relação sociedade-espaço, culminando em recortes regionais que estruturam distintas regiões culturais.

\section{A REGIÃO CULTURAL}

A Geografia tem entre suas categorias de análise o conceito de região. A importância desse conceito se deve ao fato de que o mesmo é tido como base fundamental para a elaboração de teorias, ou seja, há necessidade de serem obtidos conceitos capazes de expressar a essência dos fenômenos. E os estudos regionais são vitais na seara geográfica, contribuindo para o avanço qualitativo na interpretação do real.

A região constituiu-se em uma das categorias de análise do espaço sob a perspectiva geográfica, tornando-se um mecanismo eficiente de classificação, via critérios diversos, acompanhando as transformações teóricas e metodológicas da Geografia e a dinâmica dos seus objetos de estudo, representativos das indagações referentes a cada período da ciência geográfica.

Em seus processos classificatórios, a região tem 
NETO, H. B.; BEZZI, M. L. A região cultural como categoria de análise...

na regionalização o uso de uma taxonomia que busca a individualização de recortes espaciais delimitados por características comuns. A origem da palavra região deriva do latim regere, palavra composta pelo radical reg, que significa domínio, poder e que originou, também, outras palavras como regente e regência. Sendo que esta concepção sempre esteve atrelada à ideia de posse, conquista (GOMES, 1987).

Através da cultura a região é, então, representada. De modo geral, indica distinção e pressupõe um recorte espacial delimitado mediante critérios culturais específicos. Esses critérios são balizados pela cultura do grupo social, ou seja, referem-se às suas características (códigos culturais ${ }^{3}$ ), podendo abarcar apenas uma dessas, como por exemplo, a religião, a gastronomia, as festividades, dentre outros códigos, ou mesmo, a cultura como um "todo" abarcando o sistema de codificação de maneira geral.

No que se refere à abordagem regional, podese dizer que essa reflete a inter-relação sociedadenatureza em diferentes nuances a partir da construção do espaço geográfico. O enfoque é definido a partir dos objetivos propostos para a análise regional, uma vez que, a mesma engloba todos os aspectos humanos e as relações que mantém entre si na produção e reprodução do espaço.

Neste sentido, Bezzi (2002, p. 55) propõe entender a região como

[...] um recorte espacial (subespaço), dinâmico, que se estrutura e se reestrutura em um determinado tempo, considerando as transformações ambientais, históricas, sociais, políticas e culturais nele engendradas.

Atesta-se, assim, a complexidade da questão regional, uma vez que a mesma engloba os distintos fatores responsáveis pela organização do espaço e que, por sua vez, resultam em uma pluralidade de formas e funções, que se materializam e originam os recortes regionais. Apreender o espaço nessa perspectiva torna-se um desafio, pois requer uma visão integradora, atrelando-o ao tempo, como um pressuposto essencial para associar o físico ao humano, no constante processo de reorganização dos arranjos espaciais pela sociedade.

Por conseguinte, entende-se que os caracteres físicos e humanos que configuram o espaço regional conferem originalidade e homogeneidade à região, a partir da escolha de um determinado tema de estudo. Do ponto de vista cultural, selecionou-se como critério, a cultura de um determinado grupo, considerando os códigos que a permeiam e que são responsáveis pela sua materialização no espaço. Neste sentido, Tuan (1980) assinala que a cultura como mediadora entre o homem (enquanto ser cultural) e o espaço, tem poder de transformar a região em lugar, através do meio simbólico da qual é portadora.

O espaço regional passa a ter um significado para o grupo social, através da materialização da sua identidade, mediado pelos códigos culturais visíveis e não visíveis, mas que são responsáveis pela caracterização da região. Parte-se do pressuposto que o homem, como agente reorganizador do espaço, transforma a natureza de acordo com suas necessidades, imprimindo-lhe as características marcantes da sua cultura. Como enfatiza Sauer ${ }^{4}$ (1998), a marca da cultura na paisagem é significativa, à medida que, permanece impressa por longo período de tempo, caracterizando-a. Tem-se então, uma configuração regional, onde um grupo social confere à sua base espacial a identidade, que irá diferenciá-la das demais.

Na concepção de Bezzi (2002, p. 17) uma região cultural pode ser definida como

Um conjunto de relacionamentos culturais entre um grupo e um determinado lugar. A região é uma apropriação simbólica de uma porção do espaço por um determinado grupo, o qual também é um elemento constitutivo da identidade regional. A região sob enfoque da identidade regional, passa a ser entendida como um produto real, é concreta, existe. Ela é apropriada e vivida por seus habitantes, diferenciando-se das demais, principalmente pela identidade que the confere o grupo social.

Dessa forma, a cultura reflete como cada gru-

3 Os códigos constituem-se na simbologia responsável pela visibilidade da cultura e, também, pela sua transmissão. Encontram-se impressos nas diferentes paisagens, através do estilo das casas, vestuário típico, arte, gastronomia, música, religiosidade e festividades. Além desses, existem outros códigos que, embora não sejam visíveis, também são responsáveis pela materialização da cultura no espaço, como aportes culturais, com destaque para os valores, ideologias e convenções. Neste processo de codificação cultural, salienta-se a comunicação, oral e escrita, como um dos códigos essenciais para transmissão e projeção da cultura no tempo e no espaço. (BRUM NETO, 2007).

$4 \mathrm{Em}$ sua obra, A Morfologia da Paisagem, Sauer enfatiza que a cultura constitui-se em identidade, pois sua "marca na paisagem dura muito tempo". A partir dessa afirmação, desenvolveu uma Geografia Cultural voltada ao passado, à medida que, através de seus estudos, pode reconstituir aspectos culturais das civilizações pré-colombianas e indígenas do México e dos Estados Unidos, respectivamente, utilizando-se para tal de técnicas resgatadas da arqueologia. 
NETO, H. B.; BEZZI, M. L. A região cultural como categoria de análise...

po social organiza o espaço e imprime nesse, seus principais traços, os quais são visíveis na paisagem. A relação códigos-tempo resulta numa configuração única e original, que ao materializar-se forma a região cultural, onde cada porção do espaço mantém suas particularidades. Assim, a cultura surge como uma forma de interpretar a organização do espaço, através das experiências de cada grupo, suas atitudes e valores, onde as singularidades conferem caráter próprio a uma determinada região, ou seja, um recorte espacial com conotação cultural. Logo, numa região, os laços entre as sociedades e sua base espacial ora ampliam-se, ora estreitam-se, resultando nas distintas expressões da paisagem e dos fatores econômicos, que tendem a mudar as heranças culturais, ou então moldá-las às suas exigências frente às imposições do mercado.

Os critérios utilizados para delimitar uma região cultural estão assentados, basicamente, nos códigos que permeiam cada grupo social e sua manifestação no espaço. Entretanto, essa manifestação não necessariamente obedece aos limites político-administrativos em suas diferentes escalas. Pois, a definição ocorre através do estabelecimento da "fronteira" responsável pela delimitação do recorte espacial, ou seja, o limite que separa sua manifestação simbólica da porção do espaço onde essa manifestação não se materializa. Por isso, destaca-se que, nem sempre o estabelecimento desses limites é claro e segue os limites político-administrativos, pois depende do movimento dos povos no espaço.

O processo de regionalização pressupõe uma generalização, privilegiando sempre o que é predominante de acordo com o critério escolhido, no caso da cultura, um determinado grupo social. Porém, não quer dizer que o espaço regional seja homogêneo, pelo contrário, a diversidade é intrínseca a esse contexto, pois em geral culturas diferenciadas coexistem numa mesma porção do espaço, diferindo apenas no contingente étnico e no sistema simbólico inerente a cada grupo social.

Neste sentido, Claval (1999), estabelece que uma região cultural seja delimitada pelas diferenças de códigos e como as culturas utilizam-se dos mesmos. No instante e local onde os traços culturais mudam, tem-se a linha limítrofe da região.

Portanto, a cultura não tem limites rígidos, uma vez que esses dependem da coesão do grupo cultural e, consequentemente, da sua continuidade no espaço, caso contrário, constituiriam "ilhas" culturais, ou seja, áreas de menor expressividade espacial, em termos de distância, devido a sua pequena extensão. $O$ interior de uma região cultural é definido a partir de códigos específicos, particulares a cada cultura e, responsáveis pela construção de paisagens típicas, oriundas de uma mesma orientação cultural. A região tem, então, uma identidade, que é responsável pela sua própria definição e, também, pela sua diferenciação dos demais contextos regionais que se formam ao seu entorno.

Não se quer com isso afirmar que as regiões culturais são extremamente homogêneas. Pressupõese que a região, por ser uma parcela do espaço, é extremamente desigual, composta por formas distintas, mesmo no interior de um grupo majoritário. Portanto, há algumas singularidades que não guardam as características gerais que definem a região e, refletem a inserção de "outras" culturas no interior desta. Isso ocorre, principalmente, nas proximidades das "fronteiras", onde a necessidade de trocas é mais acentuada, atestando a dinâmica dos fluxos sócioculturais no espaço e, também, a integração social mediada, geralmente, pelas necessidades econômicas, embora predomine a coletividade cultural.

Desse modo, Claval (1999, p. 98) enfatiza que:

O grupo define a si mesmo por contraste e por exclusão: nós não temos outra possibilidade de dizer nós a não ser pelo fato de formarmos uma coletividade que se opõe a massa dos outros [...].

Pode-se dizer então, que a identidade acompanha a diferença, embora esses dois termos não sejam sinônimos. A identidade define "o que nós somos", enquanto a diferença define "o que os outros são". (WOODWARD, 2000). Tal afirmação se aplica à questão regional, pois o que é uma região sob o ponto de vista cultural, senão a individualização de uma porção do espaço em função da materialidade da cultura, viabilizada pela identidade cultural de um determinado grupo social predominante.

A individualização de recortes espaciais culturais pressupõe uma estreita relação entre espaço-cultura e códigos culturais, da qual resulta a identidade não somente do grupo social, mas também da sua base espacial, os quais são indissociáveis, uma vez que o homem necessita do substrato territorial.

Nessa perspectiva, a identidade cultural é indispensável para a manutenção de um grupo social e, também, para o entendimento da produção do espaço local e regional em seus respectivos níveis de desenvolvimento. Atualmente, a identidade tornou-se um fator de "valorização" do espaço como forma de dinamizar a economia local/regional, através da différance. Em um mundo globalizado, a cultura tem se constituído no diferencial, que resulta em atrativo socioeconomico e possibilita, muitas vezes, uma perspectiva de desenvolvimento.

Considerando tais reflexões, a região é justa- 
mente, a expressão das diferenciações do processo de produção do espaço, onde as diferenças se combinam, mas permanecem como diferenças. (BEZZI, 2002, p. 2004).

Referente ao processo de identificação regional, Castro (1992, p. 33) argumenta que

[...] enquanto construção espacial, a região é a característica dos processos sociais e incorpora sua dinâmica. Esses processos, entendidos como ação humana, econômica, política ou cultural-sobre uma base natural, estruturam em conjunto a construção do espaço em áreas geograficamente delimitadas, moldando suas peculiaridades e identificando-se com elas. [...] A região, portanto, possui uma dimensão territorial e uma dimensão social que interagem e configuram uma escala particular do espaço. [...] a região é o espaço vivido, ou seja, o das relações sociais mais imediatas e da identidade cultural.

O grupo social constrói o espaço regional mediante seus valores e anseios, a partir dos quais se identificam o que permite desenvolver um sentimento de apego à sua base espacial, um sentimento de pertencimento, de vínculo. A região cultural é vivenciada pelo grupo e, até pelos que não pertencem a mesma, mas que, ou se encontram presentes em caráter temporário ou permanente, percebem a expressividade cultural impressa nas paisagens que a compõe. Geralmente é isso que busca o turista, vivenciar a diferença, através dos aspectos subjetivos e os aspectos que materializam e se tornam visíveis no espaço, originando a paisagem cultural.

A região passa a exprimir, então, os laços tecidos entre o grupo e o seu espaço, que segundo Castro (1992, p. 32-33) origina dois tipos de identidade distintas

[...] um imediato, ou primário, estruturado individualmente, que podemos chamar de Topofilia, e outro estruturado coletivamente, na dinâmica das relações sociais, que caracteriza um espaço de vivência mais ampla, conformando uma identidade espacialmente maior, que seria a região. A região é então uma fração estruturada do território. Por constituir uma estrutura, a região possui uma identidade que permite diferenciá-la do seu entorno. Essa personalidade regional possibilita sua delimitação a partir da compreensão de especificidades que ela contém. A região é, portanto, concreta, observável e delimitável. Como qualquer segmento do espaço, a região é dinâmica, historicamente construída e interage com o todo social e territorial.
Nesta perspectiva, a região cultural possui uma identidade, conferida pelo grupo social que a individualizou e, é responsável pela sua construção e reconstrução no decorrer do tempo evolutivo das sociedades. Possui características determinantes que denunciam a origem étnica que a organizou e/ou a transformou. Tem assim, significado próprio, atrelado à cultura do grupo. Ter-se-á, então, recortes espaciais distintos, mas que ao somarem-se, evidenciam as características comuns que possibilitam ao "todo" formar um espaço único, onde os grupos sociais se reconhecem e se identificam.

É importante enfatizar também as questões inerentes ao processo de globalização e sua influência no contexto regional. À medida que se prega a homogeneização dos espaços no Globo, tem-se afirmado, cada vez mais, as diferenças, ou seja, o local e o regional, os quais ainda guardam as suas respectivas identidades. Neste sentido, Oliven (1992, p. 135), ressalta que

\begin{abstract}
Todo esse processo de mundialização da cultura, que dá a impressão de que vivemos numa aldeia global, acaba repondo algumas questões da tradição, da nação e da região. À medida que o mundo torna-se mais complexo e se internacionaliza, a questão das diferenças se recoloca e há um intenso processo de construção de identidades.
\end{abstract}

O que se percebe, atualmente, é a reivindicação de identidades, sejam nacionais, regionais ou locais, contrapondo a tendência global homogênea. A região cultural, hoje, tem afirmado sua identidade mediante a valorização dos códigos culturais e, o resgate do passado, como forma de manter a originalidade alicerçada nas heranças culturais.

A tendência à padronização do espaço altera as relações estabelecidas entre homem-natureza, mas não significa a sua homogeneização total, e sim, sua diferenciação em partes. Considerando-se que, atualmente, as economias se globalizam e os Estados perdem poder, resta, aos olhos dos geógrafos, a mais pura estrutura, ou seja, a cultura e a natureza, os verdadeiros alicerces da região (BEZZI, 2002).

Neste contexto, a região cultural surge como resposta ao padrão global homogêneo, como a firmação de um espaço de diferenciação, mediado pela identidade. Reafirma as singularidades e a originalidade do espaço, permitindo recortá-lo em partes de acordo com todos os aspectos inerentes à cultura e expressos através dos códigos culturais, responsáveis pela sua materialização e individualização espacial. 
NETO, H. B.; BEZZI, M. L. A região cultural como categoria de análise...

\section{IDENTIDADE CULTURAL E REGIÃO: O REGIONALISMO NO RIO GRANDE DO SUL}

A relação sociedade-natureza mediada pela técnica, como um fator essencial para se entender a transformação e a constante reorganização do espaço, atesta sua complexidade ao se considerar o processo de globalização, que acarreta significativas transformações socioeconômicas e culturais em escala local, regional e global e, principalmente, coloca em evidência as diferenças. Tal situação origina as identidades regionais, pautadas em uma simbologia típica inerente a um determinado grupo social.

Para Hall (1997), a globalização pode ser considerada um processo atuante em escala global, permitindo transpor fronteiras nacionais, integrar e conectar comunidades e organizá-las em novas combinações de espaço-tempo, isto é, interconectar o mundo.

Considerando a influência desse processo sobre a esfera cultural, particularmente, tem-se efeitos diversos sobre a questão da identidade, na medida em que se evidenciam as culturas distintas com suas diferenças no limiar dos séculos XX e XXI. Esse período histórico é caracterizado pela massificação da cultura pela mídia em geral, como decorrência da globalização. Trata-se, portanto, de um contraponto às teorias referentes à globalização, pois a cultura promove, justamente, o reconhecimento, via identificação dos distintos conjuntos de crenças e valores que permeiam os grupos sociais.

Essas reflexões vêm ao encontro dos debates atuais acerca da globalização. Essa considera que, na atualidade, ocorre a homogeneização dos costumes. Entretanto, o que se observa, recentemente, é um movimento inverso, que se caracteriza pela intensa reivindicação de identidades, como forma de procurar diferenciar-se desse padrão homogêneo. A busca pela originalidade tem gerado uma confusão conceitual provocada pelo que Cuche (2002) denomina de "modismos". Para o autor, a problemática está centrada no desejo de se entender cultura em tudo e, por consequência, de encontrar a identidade. Concebem-se crises de cultura como crises de identidade.

No entanto, para se ter uma identidade cultural torna-se necessário pertencer a uma cultura, pois a identidade parte desta, e tem origem "no que nós somos". A cultura é mais ampla, diz respeito à essência, e a identidade retrata essa cultura. Ou seja, a identidade emana da cultura à medida que se sobressaem as suas principais características norteadoras, que se compõe, por consequência, da identidade. Para Silva (2000), a identidade vem acompanhada da diferença, porém, elas não podem ser consideradas como sinônimos, pois a identidade classifica o que é semelhante (o que pertence ao grupo social) e a diferença estabelece o que não pertence ao grupo social, devido à distinção entre os sistemas representativos.

De maneira geral, os atuais debates relativos à questão cultural discutem as implicações do processo de globalização na cultura e na identidade, principalmente, quanto a sua homogeneização ou a afirmação da diversidade. A posição de homogeneização assenta-se na ideia de "aldeia global", com ênfase para a interdependência, onde as identidades culturais mais "fortes" suplantariam as mais "fracas", devido ao poder de influência. Assim, seriam englobadas, fazendo parte de um conjunto cultural maior e mais homogêneo.

Não se trata se uma simples substituição de códigos entre culturas. Mas da assimilação das influências externas que pode vir a modificar alguns traços, alterando valores culturais significativos e orientadores de uma cultura particular. Tal fato pode levar a uma descaracterização cultural no que se refere à identidade, fazendo com que um grupo social se assemelhe bastante, ou seja, com o que antes era tido como estrangeiro.

Neste caso pode haver uma crise de identidade com duas possíveis consequências, ou origina-se uma nova identidade, baseada na influência externa, ou o processo de (des) identificação não assume uma posição concreta, permanecendo em constante conflito, sem conseguir identificar-se com nenhuma das duas culturas em questão. Salienta-se que, em ambos os casos, ocorrem profundas mudanças na essência de uma cultura, modificando-a quanto aos seus aspectos mais importantes, responsáveis pela sua identificação. Tal situação reflete-se também, no espaço, uma vez que o homem materializa nessas suas atitudes orientadas por crenças e valores comuns aos membros de uma determinada comunidade étnica. Desse modo, há uma reorganização espacial pautada em novos "moldes" culturais, distintos da sua origem.

Em contrapartida, de acordo com a segunda visão, o processo de globalização exalta a diferença, uma vez que o global não anula o local. O excesso de padronização e informação origina um movimento contrário, direcionando a busca pela origem, objetivando encontrar a essência cultural.

Há, portanto, uma revalorização da questão cultural, a qual assume importância frente ao "padrão global". Na concepção de Hall (1997), a globalização e tudo mais que a mesma implica pode levar ao fortalecimento de identidades locais como reação defensiva dos grupos étnicos dominantes quanto à presença de outras culturas. 
NETO, H. B.; BEZZI, M. L. A região cultural como categoria de análise...

Pode-se dizer, então, que, a globalização desencadeou um movimento de reconhecimento identitário, que representa uma releitura cultural, onde os grupos sociais se reafirmam mediante laços simbólicos com os seus semelhantes e com o espaço em que vivem. Os membros de um mesmo grupo cultural tendem a seguir um sistema simbólico de crenças e valores que guiam suas atitudes, como uma espécie de "código de conduta" subjetivo e interno à legislação do Estado. Todo esse sistema simbólico se materializa no espaço, tornando-o distinto dos demais, originando a identidade do grupo cultural, através de traços típicos inerentes a determinada cultura.

A identidade cultural configura-se, então, como fator essencial para a manutenção cultural à medida que se afirma e é valorizada, tornando-se mais resistente às influências externas. Por conseguinte, a cultura é o contraponto da tendência à homogeneização, via diversidade étnica existente no globo.

Neste contexto, Woodward (2000, p. 21) refere-se a esses dois pontos de vista quando afirma que

A homogeneização cultural promovida pelo mercado global pode levar ao distanciamento da identidade relativamente à comunidade e à cultura local. De forma alternativa, pode levar a uma resistência que pode fortalecer e reafirmar algumas identidades nacionais e locais ou levar ao surgimento de novas posições de identidade.

Tal situação demonstra a existência de dinâmicas opostas, por um lado tendendo a homogeneização e, por outro, a diversificação cultural. Portanto, para compreender a construção de identidades culturais, devem-se considerar todos os aspectos internos e externos, que permeiam a cultura. A identidade não é fixa e imutável, pois oferece reação às situações a que é submetida de formas diversas.

Sempre existirão "traços" marcantes responsáveis por distinguí-la das demais identidades, alguns passíveis de transformações, outros não. A dinâmica global impõe muitos obstáculos à manutenção das identidades culturais na atualidade mediante padronização de um "estilo de vida", ao mesmo tempo em que, as mesmas encontram neste um fator de resistência e de autoafirmação pelo viés cultural.

As formas com que um povo se identifica, mediante sistemas simbólicos de representação, Ihe conferem legitimidade perante os demais, fazendo com que se apropriem de uma identidade que permite torná-los distintos e originais, a partir de uma essência cultural comum. Entretanto, ao se abordar a questão identitária, deve-se ater ao fato de que, as identidades ressaltam o que é significativo, o que se sobressai na cultura do grupo social, ou seja, os códigos culturais mais expressivos para a sua materialização.

As reflexões acerca da identidade cultural de um determinado grupo social têm na região cultural um dos expoentes práticos através da construção dos tipos regionais e do regionalismo. Para tanto, devem ser considerados diversos aspectos formadores do espaço geográfico, atrelando o físico ao humano para a compreensão desses "produtos" da região. Tal afirmação deve-se ao fato de que o tipo regional é fruto do acumular de crenças e valores no tempo e no espaço, pois reflete a evolução histórica da cultura sobre uma determinada porção do espaço construída por um determinado grupo social.

O entendimento do regionalismo requer uma análise mediada pela visão dialética, que remonta as origens para que se tenha a apreensão da construção da região pela cultura, sua evolução e as principais transformações acarretadas no sistema de codificação cultural que orienta o grupo social em sua relação com o espaço. Desse modo, torna-se mais apropriado falar em processos de regionalização e de identificação da cultura no espaço, uma vez que, esses não são imutáveis, pelo contrário, a dinâmica é uma constante na relação sociedade-natureza no decorrer da evolução da humanidade, principalmente, se considerarmos a técnica como um eficaz agente transformador.

A transformação é para a cultura, uma forma de se ajustar à realidade e, muitas vezes ocorre de forma inconsciente, pois não é planejada. Trata-se de transformações cotidianas e da adição natural de códigos para a cultura dos grupos sociais.

Para exemplificar essas transformações deve-se analisar a configuração do espaço por determinados grupos culturais, onde coexiste o velho e o novo, demonstrando que velhas formas ocupam novas funções, ou mesmo cedem lugar a novas formas, principalmente, nas cidades de médio e grande porte. A análise da organização do espaço local/regional demonstra tais transformações na medida em que surgem novas formas de se pensar o mundo, pois essas se materializam e se tornam visíveis.

A configuração regional exprime as distinções culturais ao mesmo tempo em que evidenciam as similaridades, oriundas da relação sociedade-natureza. Como exemplo tem-se o gaúcho, no Rio Grande do Sul, como expoente do tipo regional, ao qual são atribuídas inúmeras características, originando-se um estereotipo.

No entanto, ao se analisar a construção do espa- 
NETO, H. B.; BEZZI, M. L. A região cultural como categoria de análise...

ço riograndense no decorrer de sua história evolutiva, tem-se a apreensão da(s) cultura(s) do povo gaúcho, entendendo-o como um mosaico étno-cultural, formado por etnias diversas que compuseram o sul do Brasil e que, por sua vez, originaram o gaúcho. Tal afirmação deve-se a diversidade de povos que se inseriram no Estado e trouxeram consigo o seu sistema simbólico. Para Sorre (1984) através das migrações pode-se transpor a cultura no espaço, ou seja, os povos em movimento levam as suas crenças e valores e as materializam no espaço. Isso demonstra a importância da cultura como fator de organização do espaço.

A partir dessas afirmações pode-se realizar algumas conjecturas a respeito do gaúcho, como habitante do Rio Grande do Sul, considerando questões pertinentes ao processo migratório e sua influência na construção da cultura gaúcha, que acarretou profundas transformações no espaço geográfico do Estado, mediante a inserção de novos códigos culturais.

Previamente, salienta-se que o gaúcho não deve ser avaliado somente mediante o tipo regional característico que se identifica pelo senso comum, como "grosso, ou seja, de modos rudes, de bota e bombacha, sorvendo chimarrão". Para entendê-lo, deve-se evitar o estereotipo, já que o "gaúcho típico" constitui apenas uma das facetas do gaúcho, a mais primitiva, que se manteve via códigos culturais mais tradicionais e, de certa forma, influenciou as outras porções do Estado, compostas pela inserção étnica diversificada, distinta daquela que originou o gaúcho em seu primeiro estágio evolutivo, na Campanha Gaúcha ${ }^{5}$.

No Rio Grande do Sul individualizaram-se recortes espaciais com base na origem étnica das unidades territoriais riograndenses, permitindo visualizar os fluxos migratórios internos e traçar o caminho realizado mediante a dispersão dos grupos culturais no espaço gaúcho. A conjuntura de fatores políticos e culturais responsáveis pela formação do povo gaúcho, configurou um mosaico étno-cultural no Estado, dotando-o de características singulares, que originaram distintas regiões e paisagens culturais.

Dessa forma, ao se referir a uma região devese ater as suas particularidades, pois é muito simples classificar o Rio Grande do Sul culturalmente a partir do gaúcho. Porém, há uma diversidade intrínseca ao contexto regional, que possibilitou a construção da sua cultura, uma vez que o gaúcho "não nasceu pronto". O tipo regional se constituiu no decorrer da formação étnico-cultural do Estado e evolui constantemente de acordo com as inovações, que propõe ajustes para se adequar à realidade.

De modo geral, pode-se dizer que o gaúcho tem sua origem, em um primeiro momento, nas culturas nativa, portuguesa, espanhola, africana e açoriana, que compuseram, basicamente, a porção centro-sul do Rio Grande do Sul. Essas etnias vieram para o Rio Grande do Sul nos primórdios do seu processo de povoamento, quando foram definidas as fronteiras meridionais do Brasil e implantada a atividade pecuarista no extremo sul, via estâncias e charqueadas, aproveitando-se do rebanho bovino deixado pela atividade missioneira. De certa forma, houve uma associação entre os códigos culturais desses povos para a formação do gaúcho típico.

Posteriormente, se inseriram no Estado o grande contingente de alemães e italianos, que colonizaram a porção centro-norte do território riograndense, além de poloneses, judeus e japoneses em menor número, os quais adicionaram complexidade cultural à formação do gaúcho. Destaca-se que todas essas etnias contribuíram de alguma forma com a construção do gaúcho como tipo regional.

Nesse sentido, infere-se que, a diversidade que caracteriza o Rio Grande do Sul moldou paisagens distintas, repletas de significados particulares expressos através do sistema de codificação que orienta cada grupo étnico, ao mesmo tempo em que integra e divulga suas culturas, principalmente, ao se considerar as festividades, a música, as danças típicas e a gastronomia. Esses códigos culturais têm se salientado atualmente, em virtude da valorização da "marca" cultural, que serve como atrativo turístico e, ao mesmo tempo em que promove o desenvolvimento econômico, serve como difusor de costumes, formando a simbologia cultural popular. Como principal expoente dessa "marca" cultural está a Serra Gaúcha, situada na porção nordeste do Rio Grande do Sul, colonizada sobretudo por imigrantes alemães, a partir de 1824 e de italianos, a partir de 1875.

A conjuntura de fatores físicos e humanos formou uma paisagem peculiar, com vales e montanhas, nas

5 A Campanha Gaúcha situa-se no este do Estado e constitui-se em uma das primeiras porções do espaço riograndense a ser povoada, através do processo de povoamento com a implantação de estâncias e charqueadas, que originaram crenças e valores essenciais para a construção da cultura gaúcha. O apego à "vida campeira" e a "lida" (trabalho) no campo via pecuária tem suas raízes na Campanha, juntamente com códigos essenciais para a representatividade da identidade cultural gaúcha, como a gastronomia (chimarrão, carreteiro de charque, churrasco), a musicalidade (tradicionalista), linguagem (surgimento de termos regionais, cujo significado está implícito nessa região), dentre outros. 
NETO, H. B.; BEZZI, M. L. A região cultural como categoria de análise...

quais se materializaram códigos típicos dessas culturas, visíveis através do estilo das casas, da gastronomia, da música, da religiosidade, do vestuário típico, resgatado em ocasiões como as festividades e da linguagem, uma adaptação do dialeto de origem somado ao português. Mas há também, os códigos orientadores dessa materialidade, como as crenças, os valores e as ideologias, que embora não sejam visíveis, são extremamente importantes para a manutenção da cultura, uma vez que o pensamento precede a ação. Na verdade, constituem-se na essência da cultura.

Destaca-se que um dos principais fatores para o sucesso da "região serrana" do Estado gaúcho são os investimentos através do turismo. Assim, os municípios que compõem essa região centram-se nos investimentos de capital para a manutenção da infraestrutura colonial local, através de uma ampla rede de hotéis, pousadas, restaurantes entre outras atividades necessárias para viabilizar o turismo. O comércio regional reflete a produção local no ramo de vestuário e da gastronomia, principalmente os chocolates e os produtos típicos da colônia, como o queijo, o salame e os doces em conserva. Há também um controle da administração local sobre o espaço municipal, a fim de manter a infraestrutura e a paisagem colonial com os traços típicos herdados da colonização italiana. Nesse sentido, existem legislações sobre as construções em algumas unidades territoriais, a exemplo do município de Gramado.

Pode-se dizer, então, que a cultura se configura, atualmente, no Rio Grande do Sul como um agente eficaz para alicerçar o desenvolvimento socioeconômico das distintas porções do espaço gaúcho, através das peculiaridades implícitas a cada sistema de codificação cultural. A exemplo da Serra Gaúcha, outras regiões culturais do Estado estão investindo na "marca" cultural, como a Quarta Colônia de Imigração Italiana, situada na porção central do Estado gaúcho. Essa região corresponde ao quarto núcleo colonial de italianos oriundos do processo colonizador. Ressalta-se que, os três primeiros núcleos que formaram a Serra Gaúcha, correspondem, na atualidade, às atuais unidades territoriais de Bento Gonçalves, Caxias do Sul e Farroupilha.

Entretanto, o aproveitamento da paisagem típica oriunda da relação cultura-espaço não é privilégio apenas das regiões culturais formadas pelo processo de colonização. Nesse sentido, destaca-se a porção centro-sul do Estado, a qual também tem investido na atividade turística, aproveitando-se, justamente, da cultura como principal atrativo. Tal iniciativa tem se utilizado do passado estancieiro e charqueador na denominada Campanha Gaúcha. Com o fim da atividade charqueadora e o declínio da pecuária no Estado, as estâncias tornaram-se, atualmente, uma fonte de renda através do turismo rural, que explora justamente a herança do passado pecuarista. São as velhas formas adaptandose a novas funções, para se adequarem às exigências do processo evolutivo da sociedade.

Há que se ressaltar que a maior parte dos grandes proprietários rurais não vendeu suas terras, pois elas são sinônimos de poder nessa região, e representam, ainda, na atualidade, "o grande proprietário, o latifundiário". O que ocorreu foi a cedência de terras para a lavoura empresarial, via arrendamento. Tal fato representou a manutenção da propriedade, ou seja, o "status quo" do pecuarista e a exploração da terra através de outras atividades não ligadas à pecuária, garantindo lucro ao mesmo, não dependendo das variações do mercado. Essas preocupações são de responsabilidade do arrendatário, que paga o "aluguel" pelo uso da terra e a explora diretamente. Do ponto de vista cultural, representam a preservação do patrimônio histórico e da memória cultural de uma fase importante da evolução do Estado demonstra, também, a significativa presença da cultura portuguesa materializada no espaço riograndense.

Portanto, permanece ainda o caráter concentrador da terra na Campanha gaúcha, o que torna as grandes propriedades alvo de invasões pelo Movimento dos Sem Terra (MST). A iniciativa do arrendamento justifica, em parte, a função social da terra, exigida pelo Instituto Nacional de Reforma Agrária (INCRA), pois as grandes propriedades são exploradas via atividade agrícola, mas não diretamente pelo proprietário.

Atualmente, existem alguns assentamentos nas tradicionais áreas de pecuária do Rio Grande do Sul, como forma de pressão social e política pela reforma agrária. As marchas organizadas pelos sem-terra são comuns nessa região cultural, na medida em que se reivindica a desapropriação de propriedades que esse movimento alega serem improdutivas, tornando-se alvo de invasão. Além disso, tem-se, anualmente, a marcha dos sem sem-terra denominada de "abril vermelho", com objetivo de realizar diversas invasões para pressionar o estabelecimento de assentamentos rurais para os pequenos agricultores.

Percebe-se, que esta região cultural apresenta uma dicotomia quanto à posse da terra. Em contrapartida, tem-se os grandes proprietários de terras da Campanha, num movimento contrário aos sem terra. Para tanto, organizaram movimentos em defesa da propriedade, atrelados à questão legal de posse da terra e do cumprimento de sua função social. Denominado de "maio verde", esse movimento bloqueou e monitorou a marcha dos sem-terra, com intuito de impedir as in- 
NETO, H. B.; BEZZI, M. L. A região cultural como categoria de análise...

vasões. Essa situação reforça a questão da identidade cultural atrelada à grande propriedade no oeste do Rio Grande do Sul, na qual os produtores reafirmam os códigos construídos ao longo do processo de povoamento dessa porção do Estado. É um movimento armado que, geralmente, acompanha a caminhada do MST a certa distância e, dispõe de mais recursos em função das suas condições financeiras.

Destaca-se a existência desses dois grupos antagônicos, cujos interesses diferem, mas também, centram-se na posse da terra. O MST reivindicando a desapropriação e a função social da terra, enquanto os ruralistas reivindicam a manutenção da propriedade e da concentração da terra pelo direito legítimo de posse. A questão da disputa pela posse da terra na Campanha é polêmica e envolve, sobretudo, códigos seculares e tradições originadas no passado estancieiro e charqueador dessa porção do espaço gaúcho.

Considerada como o "berço do gaúcho", a Campanha remete a costumes típicos do tradicionalismo e serve como referência em termos de paisagem característica do Pampa, com grandes extensões de campo para pastagem do gado. A partir da atividade pecuarista tem-se a lida campeira, o peão a cavalo, o churrasco, a roda de chimarrão e a trova ao redor do fogo de chão como alguns códigos culturais identificadores. A bombacha não é uma vestimenta usada somente nas festividades comemorativas do tradicionalismo, é uma peça usual e encontrada com facilidade no cotidiano dos habitantes, principalmente, nos mais velhos, que expressam com orgulho o fato de serem gaúchos típicos. A afirmação "é na Campanha que o gaúcho se reconhece" efetiva-se através do cotidiano dos seus habitantes, que expressam os códigos culturais de forma mais significativa nessa porção do Estado.

Por um longo período de tempo, a terra significou poder político na Campanha e criou sobrenomes influentes em nível local, regional e nacional. Como exemplos citam-se os ex-presidentes da República Gétulio Vargas e João Goulart, naturais do município de São Borja, localizado nessa região cultural. É importante salientar que o poder advindo da classe pecuarista ainda, na atualidade, é muito expressivo e se faz presente nas decisões importantes a respeito da dinâmica socioeconômica na maioria das unidades territoriais dessa região cultural.

Apesar dessa porção do Estado gaúcho desenvolver a atividade pecuarista desde os primórdios do povoamento nela, também, se desenvolvem as lavouras empresarias do arroz e da soja e, mais recentemente, o florestamento e a fruticultura apresentam-se como novas cadeias produtivas para o desenvolvimento econômico dessa região. Entretanto, a presença dos latifúndios tornou-se uma "marca" dessa porção do espaço gaúcho.

Nessa perspectiva, pode-se dizer que, o regionalismo acompanha a diferença e ressalta, justamente, as particularidades regionais, através de códigos específicos que acompanham cada grupo cultural. As expressões originadas são repetidas de forma inconsciente, pois pertencem ao âmbito cultural e, portanto, não são imposições ou modelos prontos que se deve cumprir. A imersão cultural, ou seja, a vivência no cotidiano da sociedade é que estabelece a identificação com os códigos desenvolvidos pela mesma.

Considerando-se o contexto regional do Rio Grande do Sul e a identificação do seu habitante como gaúcho, observa-se a formação de um tipo característico, dotado de inúmeros códigos culturais moldados ao longo do seu processo evolutivo. O gaúcho como "figura representativa" pode ser definido através de características comuns atreladas a questões como tradicionalismo e nativismo, acentuadas nos gestos, nas crenças e nos valores.

Tal situação pode ser identificada ao sair do Rio Grande do Sul, sendo possível perceber as disparidades regionais materializadas, principalmente, através da linguagem. Quando os gaúchos se comunicam com outros grupos sociais, cuja cultura é marcante no que se refere à fala, como por exemplo, os cariocas, ou mesmo nordestinos, mineiros e paulistas, o gaúcho percebe as entonações, gírias, frases feitas e demais expressões típicas que não lhes são comuns. Até mesmo palavras simples utilizadas no cotidiano apresentam denominações diferentes, como a mandioca e a macaxeira, a bergamota e a mexerica. São "modos" diferentes de se comunicar, embora o português seja a língua oficial do Brasil.

No que se refere ao contexto regional interno, o Rio Grande do Sul acompanha uma diversidade cultural através da composição étnica. Tal situação deve-se a estruturação da ocupação inicial do Estado pelas principais etnias que se instalaram nas terras sulinas, em virtude da atividade pecuarista, assentada nas estâncias e charqueadas e, a posterior inserção de grupos étnicos oriundos da Europa, mas não portugueses. A localização das etnias formadoras do Rio Grande do Sul deve-se às políticas de incentivo à ocupação do território riograndense, inicialmente, nas áreas fronteiriças, com os portugueses e, posteriormente, no centro e nordeste, com alemães e italianos e, por fim, no norte, com culturas diversificadas.

Assinala-se que a Serra Gaúcha não tem sua origem italiana por escolha dos imigrantes que se ins- 
NETO, H. B.; BEZZI, M. L. A região cultural como categoria de análise...

talaram no território gaúcho. Essa porção do espaço Ihes foi destinada e, coube a cada etnia desenvolver seus núcleos coloniais iniciais e, moldar a paisagem de acordo com suas preferências, expressas pelas crenças e valores que guiam suas ações.

A expressividade observada nas distintas regiões que compõem o Rio Grande do Sul, mediante o critério cultural, deve-se a necessidade de manutenção do sistema de codificação, que serve como um fator de coesão social, pois partilhar as mesmas práticas significa estabelecer vínculos de união social, mediados pela herança simbólica que une um determinado grupo social. Os códigos mais significativos se materializam no espaço e servem como "monumentos" à cultura, uma vez que, possibilitam sua identificação via formas típicas. Desse modo, as regiões culturais, de uma forma geral, apresentam paisagens dotadas de significados particulares a cada cultura, as quais denotam sua origem étnica. Destaca-se que, decifrar esses significados permite entender o sistema simbólico intrínseco a cada grupo social que partilha uma cultura em comum.

Por conseguinte, pode-se dizer que a simbologia das culturas que compõem o Rio Grande do Sul agregou "valor" ao gaúcho ao longo do seu processo evolutivo sociocultural, pois, não se trata de uma "figura" histórica congelada no tempo, que se originou na Campanha Gaúcha mediada somente pela lida campeira, tendo como principal ícone as lutas pela defesa do território e das causas justas. A Revolução Farroupilha constituise em um marco histórico para o gaúcho, dotando-o da característica guerreira e repleto de virtudes, como honra e bravura. Mas, após 1835 já decorreram quase dois séculos em que a história do Rio Grande do Sul foi reescrita por diversos povos que vieram compor não somente o território, mas também, a cultura gaúcha. Ao mesmo tempo em que preservam as características atreladas a sua origem, os grupos culturais gaúchos, se reconhecem como tais, preservando as tradições atreladas ao tipo regional que se formou no extremo sul do Brasil.

Pode-se dizer que, em cada região cultural do Estado há uma forma de "ser gaúcho", que expressa o nativismo de acordo com a sua concepção, mediada por valores e crenças particulares, que guardam alguma homogeneidade em relação à questão cultural gaúcha, pois partilham códigos comuns. A relação que se estabelece entre o gaúcho, considerado o "todo" e os diversos grupos culturais que mantém suas peculiaridades permite afirmar que o Rio Grande do Sul compõe um mosaico étno-cultural, formado pela inserção de várias etnias que contribuíram de forma significativa para a sua configuração sociocultural e econômica, individualizan- do regiões específicas repletas de particularidades, mas que guardam certa homogeneidade no que se refere à questão cultural que envolve o gaúcho.

Diante dessas reflexões e conjecturas a respeito da questão cultural que permeia o Rio Grande do Sul, faz-se uma indagação. Mas, afinal, quem é o gaúcho? De maneira geral, principalmente, se considerando o senso comum, o gaúcho é uma figura regional, que se identifica mediante alguns traços característicos, que permitem traçar um perfil, muitas vezes demonstrado através de um estereótipo, que o veste com trajes típicos, fala "grosseira", vocabulário regional com termos como bah e tchê, além do tradicional chimarrão. Essa é uma visão geral, sobretudo, vinculada a mídia, que procura traçar caricaturas que identifiquem traços regionais marcantes, como o mineiro uai ou trem bão, ou mesmo o nordestino, com o popular ó xente, so. Constitui-se, também, em uma concepção para quem não conhece o Rio Grande do Sul e a diversidade que o compõe, pois se retrata o gaúcho via características que se popularizaram e o identificam em nível nacional.

Entretanto, pode-se tecer algumas considerações a respeito do gaúcho, como o tipo regional do Rio Grande do Sul, um ícone que representa a cultura gaúcha. As representações simbólicas que caracterizam o gaúcho de forma geral e que são representadas em Centros de Tradições Gaúchas (CTGs) e, principalmente, na Semana Farroupilha, são, na verdade, costumes que estão arraigados nas diversas porções do Estado, ou seja, os hábitos típicos considerados como originalmente gaúchos, são cultuados, cotidianamente, em todas as regiões culturais do Rio Grande do Sul e até mesmo fora do espaço regional.

No momento em que se partilha e cultiva as mesmas tradições, ocorre um processo de identificação com a cultura, tornando-se parte integrante da mesma, pois ao mesmo tempo em que a mesma influencia é influenciada pela imaterialidade que a compõe. No entanto, como podem duas concepções culturais coexistir em um mesmo grupo social, ou seja, como ser "alemão" e gaúcho ao mesmo tempo, ou "italiano" e gaúcho e, assim por diante?

O processo de identificação que associa as etnias formadoras do Rio Grande do Sul ao gaúcho deve-se ao fato de que, as mesmas também se constituem em partes integrantes da cultura gaúcha, pois os códigos culturais que identificam o tipo regional foram construídos ao longo do tempo e, não estavam simplesmente, prontos quando teve início o processo migratório no Estado. Pelo contrário, havia uma predominância portuguesa e africana, em número, mas somente, na porção sul e oeste, acompanhando a área de fronteira com os 
NETO, H. B.; BEZZI, M. L. A região cultural como categoria de análise...

espanhóis, obtendo, inclusive, influência desses últimos, além dos nativos e açorianos. Desse modo, há que se considerar a influência alemã, italiana, polonesa e japonesa no sistema de codificação cultural do gaúcho, uma vez que as mesmas integram a cultura gaúcha, devido a expressividade da sua contribuição.

Portanto, o gaúcho é o habitante do Rio Grande do Sul, que cultua traços característicos e, através desses, demonstra as particularidades intrínsecas ao contexto regional, observadas via inserção de códigos culturais diferenciados de acordo com a etnia de origem. No entanto, considera-se que, no contexto geral, forma o povo gaúcho. Esse se reconhece e se identifica mediante simbologias comuns, materializadas via costumes e tradições que originam formas e hábitos particulares, que remetem a um modo de vida singular se comparados a outras porções do País.

\section{CONSIDERAÇÕES FINAIS}

A cultura é uma criação coletiva e renovada dos homens. Ela molda os indivíduos e define os contextos da vida social que são, ao mesmo tempo, os meios de organização e de dominar o espaço. Ela constitui o indivíduo, a sociedade e o território onde se desenvolvem os grupos. As identidades coletivas que daí resultam limitam as marcas exteriores e explicam como diferentes sistemas de valor que podem coexistir num mesmo espaço. (CLAVAL, 1999).

As considerações finais podem ser consideradas como um momento crucial, pois como afirma Raffestin (1993, p. 266), "Se existe alguém que, por excelência, nunca poderia nem deveria concluir uma obra, esse alguém é autor". No entanto, todo estudo investigativo tem como meta tecer informações que venham a contribuir para o enriquecimento teórico-metodológico proposto.

Nesse contexto, a temática debatida nesse artigo, tendo como base as regiões culturais, direcionou o entendimento da mesma, entendendo-a como um conceito que expressa movimento em direção a uma realidade.

Escolheu-se o caminho da conceituação de região cultural, por entendê-lo como um conceito essencial para a apreensão das relações espaciais. Também se fizeram algumas tentativas de materializá-lo através da análise do espaço regional intrínseco ao Rio Grande do Sul. No entanto, o trabalho também aponta como primordial, fornecer subsídios para estudos que proponham depreender o conceito de região cultural em um quadro espaço-temporal.

Ao se buscar a compreensão do conceito de região, afirmou-se que é indispensável contextualizá-lo histórica e espacialmente. É necessário perceber que a região cultural é resultante de interações dinâmicas que ocorrem no espaço geográfico. Nessa perspectiva, o conceito de região cultural é entendido como um quadro de referência fundamental, da sociedade, respaldada na identidade cultural.

Considerando a importância da identidade cultural para o contexto regional, podemos dizer que através dessa a região pode ser definida, representada e diferenciada. Assim, a identidade cultural coloca novamente os seres humanos como atores na produção e reprodução da vida social e dos lugares. Valoriza-se a perspectiva humanística sobre a sociedade, passando essa a ser um conjunto de significados expressos em um determinado recorte espacial. Estudar a região sob a perspectiva da identidade cultural é manipular o código de significações nessa representado, ou seja, para compreender uma região cultural, é preciso vivenciá-la.

No que se refere às transformações inerentes ao contexto regional, pode-se afirmar que a dinâmica tempo-espaço-cultura é contínua e integra o cotidiano das sociedades, reconstruindo-os à medida que novas transformações se fazem necessárias para se adequar à realidade proposta. As mudanças ocorrem, num primeiro momento, nos aspectos imateriais, responsáveis pelos comandos mentais que guiam as atitudes e, posteriormente, se materializam no espaço. A aceitação da mudança é pré-existente à sua efetivação no contexto cultural, uma vez que, existem crenças seculares que envolvem estruturas complexas para se transformarem, já que estão arraigadas na cultura. Para que a mudança se efetive, torna-se imprescindível a "necessidade", isto é, a inovação surge mediante uma dificuldade, como instrumento eficaz de ajuste social.

Quando se retrata a cultura de um determinado grupo social deve-se ater a todo seu processo evolutivo, visto que, a atual configuração socioespacial tem explicação nas formas e funções pré-existentes e na dinâmica imposta pela relação sociedade-natureza no decorrer da história evolutiva de uma comunidade étnica.

Para tanto, considerou-se a contribuição das etnias inseridas no território gaúcho, para analisar a questão regional sob a ótica da cultural no Rio Grande do Sul. Nessa perspectiva, o espaço adquire uma conotação simbólica, via cultura, que origina recortes espaciais de acordo com a origem étnica das unidades 
territoriais riograndenses, permitindo visualizar os fluxos migratórios internos e traçar o caminho realizado mediante a dispersão dos grupos culturais no espaço gaúcho. A conjuntura de fatores políticos e culturais responsáveis pela formação do povo gaúcho, configurou um mosaico etno-cultural no Estado, dotando-o de características singulares, que originaram as regiões e paisagens culturais gaúchas.

Ao partilhar os mesmos códigos, a sociedade riograndense assumiu uma identidade comum: a gaúcha. Porém, embora exista essa identidade "geral" que representa o "todo", observam-se as particularidades que o compõe através da manutenção da cultura original das diversas etnias que compuseram o Rio Grande do Sul. Não há um conflito entre culturas, mas a coexistência, à medida que, essas etnias são, também, formadoras da cultura gaúcha, se reconhecendo como tal.

No Rio Grande do Sul há dois processos de identificação regional. O primeiro, refere-se ao "ser gaúcho", que reconhece o habitante do território riograndense em nível nacional. Já, o segundo, em nível regional, que remete a origem étnica, via descendência, interna ao Estado, ou seja, pertencer a uma região de colonização alemã ou italiana, ou mesmo polonesa, dentre outras etnias como as formadoras da região de povoamento, como portugueses, espanhóis, africanos e açorianos.

Há convenções simbólicas partilhadas pela identificação do gaúcho, com símbolos tradicionais, como o chimarrão, o churrasco e a linguagem repleta de termos utilizados estritamente no âmbito regional, ao mesmo tempo em que existem convenções que refletem as particularidades de cada região cultural que compõem o Estado, via diversidade étnica. Esses símbolos ou códigos são responsáveis pela sua identificação em nível regional e, também, local, salientando a diferença, uma vez que cada grupo cultural é permeado por um sistema simbólico de representação particular, reconstruído no constante processo evolutivo das sociedades.

A cultura gaúcha, considerada a partir do processo de identificação da sociedade riograndense, é mediada por códigos culturais expressivos nas crenças e valores cunhados no decorrer da evolução espaço-temporal. Desse modo, a cultura é representada e materializada no espaço, originando formas típicas, passíveis de reconhecimento pelos demais grupos sociais. Pode-se dizer, então, que, decifrar e interpretar esses códigos significa entender a dinâmica da cultura em questão, os valores e crenças que orientam as atitudes e ações. Estas, por sua vez, são repetidas maquinalmente como um padrão orientador comum.

Embora a percepção seja individual ela apresenta estreita relação com o contexto comum e age em relação às situações, ou seja, o "ser gaúcho". Os códigos são passados de geração em geração como ensinamentos. Porém, estes não são fixos no tempo e no espaço, pois as formas e as funções podem mudar de acordo com a dinâmica cultural. Trata-se de um ajuste cultural a realidade, pois a cultura não é inerte, pelo contrário, por tratar-se da relação sociedade-natureza e essencialmente dinâmica.

Nessa perspectiva, afirma-se que qualquer alteração nos códigos demonstra que houve transferências de hábitos e/ou comportamentos que, por conseguinte, denotam a evolução de um complexo sistema cultural composto por inúmeros códigos que, transformam-se para adequar-se as novas realidades. O Rio Grande do Sul configura-se como uma unidade (gaúcho) na diversidade, pois se formou mediante processos de povoamento e colonização caracterizados pela inserção de etnias diversas.

A dinâmica socioespacial exerce então, forte influência na construção e manutenção do regionalismo, acarretando transformações visando sua readaptação as novas realidades que se configuram no espaço.

Neste contexto, percebe-se que há uma interrelação entre cultura-identidade-código na formação de uma região cultural, uma vez que esta associação confere, ao espaço, características que permitem ao mesmo identificar-se e ser identificado pelos demais, mediante a formação e materialização de características culturais singulares, emanadas por uma determinada cultura.

\section{REFERÊNCIAS}

BEZZI, M. L. Região como foco de identidade cultural. Geografia, v. 27, n. 1, p. 5-19, 2002.

- Região: uma (re) visão historiográfica - da gênese aos novos paradigmas. Santa Maria: Ed. da UFSM, 2004.

BRUM NETO, H. Regiões Culturais: a construção de identidades culturais no Rio Grande do Sul e sua manifestação na paisagem gaúcha. 328 f. Dissertação (Mestrado em Geografia) - Universidade Federal de Santa Maria, Santa Maria, 2007.

CASTRO, I. E. de. O mito da necessidade: discurso e prática do regionalismo nordestino. Rio de Janeiro: Bertrand Brasil, 1992. 
NETO, H. B.; BEZZI, M. L. A região cultural como categoria de análise...

CLAVAL, P. A Geografia Cultural. Tradução de PIMENTAL, L. F.; PIMENTA, M.A. Florianópolis: Ed. da UFSC, 1999.

CUCHE, D. A noção de cultura nas ciências sociais. Tradução de RIBEIRO, V. 2. ed. Bauru: Ed. da USC, 2002.

GOMES, A. As razões da região. 194 f. Dissertação (Mestrado em Geografia) - Universidade Federal do Rio de Janeiro, Rio de Janeiro, 1987.

HALL, S. Identidades culturais na pós-modernidade. Tradução de SILVA, T. T. da.; LOURO, G. L. Rio de Janeiro: DP \& A, 1997.

OLIVEN, R. G. A parte e o todo: A diversidade cultural no Brasil - Nação. Petrópolis: Vozes, 1992.

RAFFESTIN, C. Por uma Geografia do poder. São Paulo: Ática, 1993. Série Temas, 29.
SAUER, C. O. A morfologia da paisagem. In: CORREAA, R. L.; ROSENDAHL, Z. (Org.). Paisagem, Tempo e Cultura, Rio de Janeiro: Ed. da UERJ, 1998. p. 12-74.

SILVA, T.T. A produção social da identidade e da diferença. In: SILVA, T. T. (Org.). Identidade e diferença: A perspectiva dos estudos culturais. Petrópolis: Vozes, 2000. p. 73-102.

SORRE, M. Migrações e mobilidade do ecúmeno. Tradução de MEGALE, J. F. (Org.). São Paulo: Ática, 1984. p. 124 -139.

TUAN, Yi-Fu. Topofilia: um estudo da Percepção, Atitudes e Valores do Meio Ambiente. Tradução de OLIVEIRA, L. de. São Paulo: Difel, 1980.

WOODWARD, K. Identidade e diferença: uma introdução teórica e conceitual. In: SILVA, T. T. (Org.). Identidade e diferença: A perspectiva dos estudos culturais. Petrópolis: Vozes, 2000. p. 7-72. 